\title{
Emissão de Dioxinas, Dibenzofuranos, PAHs e PCBs no fabrico de aço em forno de arco eléctrico
}

\section{Resumo}

0 objectivo deste trabalho é o estudo dos mecanismos de formação e destruição de compostos orgânicos de elevada toxicidade, tais como dioxi- nas, dibenzofuranos, PAHs e PCBs, no processo de fabrico de aço por arco eléctrico. Este estudo visa relacionar o nivel das emissões destes compostos com variáveis operacio- nais que sejam consideradas como críticas, no sentido de possibilitar a redução dessas mesmas emissões através de um adequado controlo do processo.

\section{Introdução:}

O termo "dioxinas" ou dibenzo-para-dioxinas policloradas refere-se a um grupo de 75 composições químicas e o termo "furanos" dibenzo-para-furanos policlorados de 135 composições, na maioria de elevada toxicidade [1].

A relação entre a estrutura e a toxicidade dessas substâncias explica-se na figura 1. No caso das dioxinas, dois anéis de benzenos estão ligados com dois átomos de oxigénio, os furanos têm uma ligação com o oxigénio e uma ligação directa entre os átomos de carbono. Ambos os grupos têm 8 posições para ligar com átomos de hidrogénio ou cloro (ou com os outros halogéneos). Para ter a possibilidade de identificação dessas 8 posições específicas, elas são marcadas com os números de 1 a 8 . A toxicidade depende: por um lado do número dos átomos de cloro substituindo o hidrogénio (número 1 a 8) e por outro lado da posição dos átomos do cloro na molécula (posições 1 a 8).

A dioxina mais tóxica e mais perigosa é a 2,3,7,8, - tetraclorodibenzo - $p$ - dioxina $(2,3,7,8-T C D D)$. A estrutura tem 4 átomos de cloro nas posições 2, 3, 7 e 8. Nas extensas investigações verificou-se que a toxicidade das outras dioxi- nas/furanos, também se podem provar, principalmente, com os congéneres com cloro nas posições 2, 3, 7 e 8. Por isso é necessário medir todos os congéneres da tabela 1. Mas como a toxicidade dos congéneres específicos é diferente (relação de 1 a 1000), existe um sistema de valorização internacional [2].

Devido à toxicidade, a quantidade dos congéneres verificado no processo de análise laboratorial, é multiplicado com o factor correspondente à tabela 1 (I-TEF - International Toxic Equivalent Factor). Com o resultado da multiplicação soma-se uma quantidade, que representa a toxicidade de todos os congéneres determinados em relação ao 2,3,7,8, - tetraclorodibenzo - $p$ - dioxina (I-TEQ - International Toxic Equivalent Value).

A grande diferença na toxicidade entre os grupos dioxinas/furanos exige métodos específicos para a análise laboratorial. Importante também, são os aspectos da amostragem porque uma alteração dos congéneres tem de ser evitada.

Em particular, a dose máxima admissível diária no corpo humano foi recentemente estabelecida pela Organização Mundial de Saúde como 4 pgTEQ/kg de<smiles>[R6]c1c([R9])c([R3])c2c(c1[R9])Oc1c([R9])c(Br)c(Br)c([R9])c1O2</smiles>

$\mathrm{R}=\mathrm{H}, \mathrm{Cl} \quad \mathrm{PCDDs} 75$ congeners

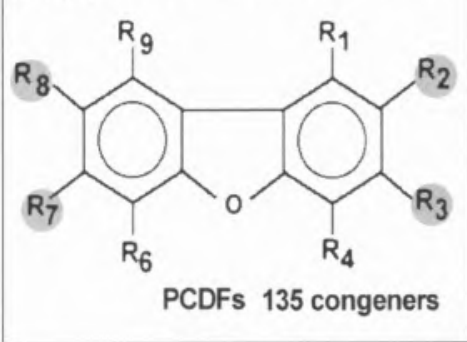

figura 1 Estrutura das dioxinas/furanos

peso corporal para todos os congéneres incluindo PCBs [3].

A formação de dioxinas e furanos bem como outros compostos tóxicos são resultado de combustões incompletas de matéria orgânica As dioxinas/furanos são sempre subprodutos indesejáveis, que nunca se produzem para utilização corrente. Isto acontece quando a temperatura se situa entre $200^{\circ} \mathrm{C}$ e $600^{\circ} \mathrm{C}$.

No entanto se existir ar suficiente e a temperatura for superior a $950^{\circ} \mathrm{C}$ e o 
tempo de residência suficientemente longo, toda a matéria orgânica será destruída no forno de arco eléctrico. Este é o princípio concluido através dos incineradores de resíduos hospitalares e urbanos.

A formação das dioxinas/furanos exige em geral a presença dos compostos orgânicos como fenol, clorobenzenos, PCBs, do cloro, dum catalisador (por exemplo cobre) e uma temperatura de reacção entre 200 a $600^{\circ} \mathrm{C}[4,5]$.

Como as dioxinas/furanos indicam efeitos tóxicos já em teores muito baixos, são necessários apenas teores consideravelmente baixos dos produtos base, para produzir algumas quantidades dessas substâncias. É bem conhecido que vestígios de composições orgânicas (às vezes condicionadas para processos de pirólise), do cloro e do cobre, estão dispersas em muitos produtos, nas muitas espécies dos resíduos e também no ambiente em geral. Neste contexto é compreensivel, que até os incêndios florestais e outras actividades tais como queimas domésticas de madeiras e resíduos produzam dioxinas/furanos em teores baixos. Por outro lado encontram-se também teores mais elevados em processos químicos caracterizados pelos teores elevados dos produtos base, assim como em processos de destruição térmica de susbstâncias cloradas, como é o caso de resíduos industriais, domésticos clorados e hospitalares [1].

Os PCBs, ao contrário das dioxinas, foram produzidos intencionalmente dadas as suas propriedades físico-químicas que Ihes conferem um vasto leque de aplicações. Por serem praticamente incombustiveis, com baixa pressão de vapor á temperatura ambiente, baixa volatilidade e solubilidade, boa estabilidade térmica, estáveis quimicamente e resistentes ás bases e ácidos, têm sido utilizados como fluidos dieléctrico em transformadores e condensadores, em adesivos, óleos de corte, lubrificantes hidráulicos, tintas etc.

Entre as principais fontes de emissão de micropoluentes destacam-se os processos metalúrgicos e siderúrgicos. Desde

Tabela 1 Índice de Toxicidade para os diferentes congéneres de Dioxinas/Furanos (I-TEF, International Toxic Equivalent Factor)

\begin{tabular}{|c|c|c|c|}
\hline \multicolumn{2}{|l|}{ Dioxinas } & \multicolumn{2}{|l|}{ Furanos } \\
\hline Congéneres & I-TEF & Congéneres & I-TEF \\
\hline \multirow[t]{2}{*}{$2,3,7,8-\mathrm{TCDD}$} & 1 & $2,3,7,8-\mathrm{TCDF}$ & 0,1 \\
\hline & & $2,3,4,7,8$ - PeCDF & 0,5 \\
\hline $1,2,3,7,8-\mathrm{TeCDD}$ & 0,5 & $1,2,3,7,8-\mathrm{PeCDF}$ & 0,05 \\
\hline $1,2,3,7,8,9-\mathrm{HxCDD}$ & 0,1 & $1,2,3,7,8-\mathrm{PeCDF}$ & 0,05 \\
\hline $1,2,3,4,7,8-\mathrm{HeCDD}$ & 0,1 & $1,2,3,4,7,8$ - HeCDF & 0,1 \\
\hline \multirow[t]{2}{*}{$1,2,3,6,7,8-\mathrm{HxCDD}$} & 0,1 & $1,2,3,7,8,9-\mathrm{HxCDF}$ & 0,1 \\
\hline & & $1,2,3,6,7,8-\mathrm{HxCDF}$ & 0,1 \\
\hline \multirow[t]{2}{*}{$1,2,3,4,6,7,8-\mathrm{HpCDD}$} & 0,01 & $2,3,4,6,7,8-\mathrm{HxCDF}$ & 0,1 \\
\hline & & $1,2,3,4,6,7,8-\mathrm{HpCDF}$ & 0,01 \\
\hline OCDD & 0,001 & OCDF & 0,001 \\
\hline
\end{tabular}

há vários anos, que os responsáveis da indústria, os cientistas e as autoridades procuram meios apropriados para minimizar os impactos ambientais de dioxinas/furanos.

O estudo da composição da sucata na cinética da formação dos PCDF/PCDF foi levado a cabo numa unidade de produção de aço por FAE (forno de arco eléctrico) para estudar os efeitos do tipo de sucata em particular o uso de sucata industrial do ramo automóvel, que contem grandes quantidades de plásticos. Destaca-se ainda o estudo feito também à influência dos metais, nomeadamente metais pesados na cinética de formação de PCDD/PCDF.

\section{Metodologia utilizada}

Os objectivos em causa têm vindo a ser atingidos pela realização de campanhas de amostragem e análise de compostos orgânicos nas chaminés de despoeiramento dos efluentes gasosos de um forno nacional de produção de aço por arco eléctrico. Nestas campanhas são efectuadas, igualmente, medições de outros poluentes com influência no pro- cesso tais como as partículas totais em suspensão, assim como dos respectivos parâmetros de escoamento.

Como técnica de amostragem tomou-se como base o método descrito na norma europeia EN 1948, tendo, contudo, sido realizadas várias adaptações e melhoramentos no sentido de tornar este método de amostragem mais consentâneo com o objectivo das medições, ou seja, o esclarecimento do mecanismo de geração e emissão de compostos durante um processo cíclico. Foram igualmente registadas as composições das sucatas e aditivos utilizadas no processo de forma a estabelecer as respectivas correlações.

Um desenvolvimento experimental importante consistiu no desenvolvimento de técnicas isocinéticas para amostragem e análise de PAHs e PCBs, tendo sido utilizados padrões marcados em ${ }^{13} \mathrm{C}$ com 1,2,3,7,8-PeCDF, $1,2,3,7,8,9-\mathrm{HxCDF}$, 1,2,3,4,7,8,9-HpCDF. As determinações analiticas foram efectuadas em equipamento HRGC/HRMS, VG-AutoSpec utilizando colunas capilares DB 5. 


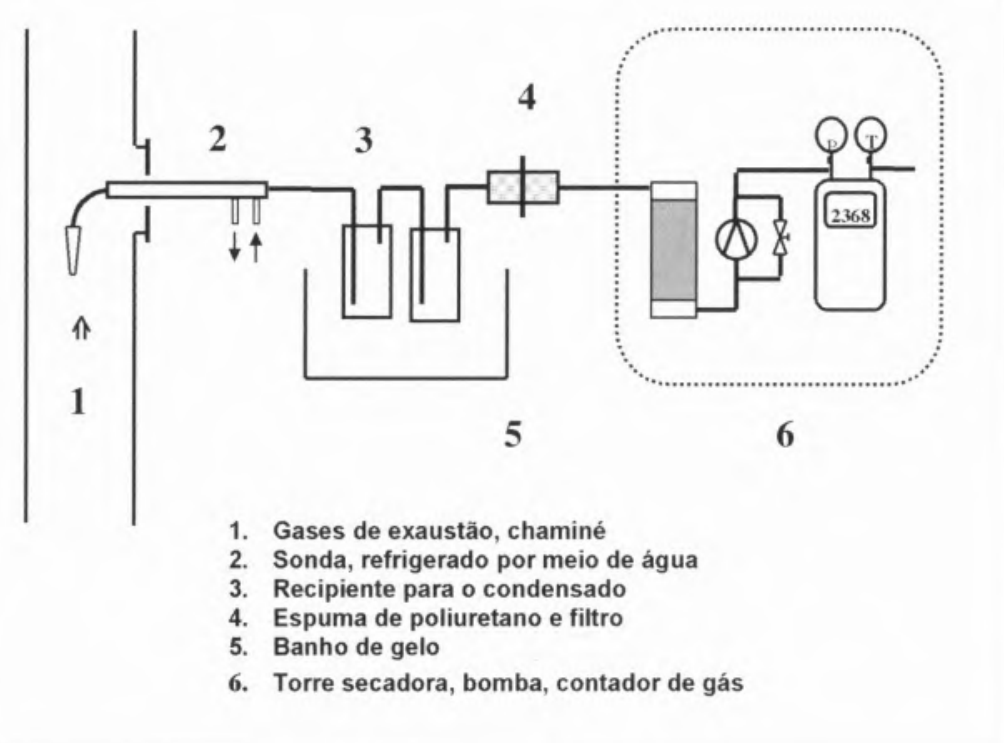

No que diz respeito aos PAHs foram quantificados 16 congéneres definidos de acordo com as indicações da EPA utilizando extractos deuterados entre $D^{8}$ e $D^{14}$. Em termos de PCBs foram determinados os isómeros 28, 52, 101, 138, 153,180 e homólogo total, sendo utilizados padrões internos marcados igualmente com ${ }^{13} \mathrm{C}$.

Para os volumes de amostragem utilizados obtiveram-se limites de detecção de $5 \mathrm{pg} / \mathrm{m} 3$ para as dioxinas e dibenzofuranos e $0,01 \mu \mathrm{g} / \mathrm{m} 3$ para os PAHs e PCBs.

\section{Procedimentos de amostragem e análise}

\section{a) Dioxinas e Furanos}

0 princípio da amostragem das emissões atmosféricas (por exemplo nas chaminés) é determinado pelo facto de que as dioxinas/furanos em geral são enriquecidas por partículas finas, exigindo métodos que são qualificados para a amostragem das partículas (medições representativas, amostragem isocinética), equipados com um adsorvente adicional para recolher as dioxinas/furanos em forma de gás.

Na figura 2 ilustra-se o princípio do método da sonda arrefecida que é parte da norma técnica da União Europeia, EN 1948 [2].
Uma parte das emissōes gasosas (partículas e gases) é aspirada através de uma sonda de vidro por uma bomba. Depois as partículas e os gases passam para um recipiente onde o condensado e as partículas são recolhidos. 0 sistema de recolha é constituído por um conjunto de frascos colectores (borbulhadores), que recolhe os condensados e as partículas, pela espuma de poliuretano, um adsorvente especial com prova de eficiência para a separação de substâncias orgânicas, intercalado com um filtro de partículas.

Em seguida une-se o filtro de alta eficiência e duas placas do adsorvente em espuma de poliuretano. Conectado a este equipamento encontra-se a torre de sílica a bomba de gás e o contador de gás que regista a quantidade de gás aspirado. Adiciona-se ao frasco de condensados os padrões de amostragem antes da amostragem. O fluxo do gás é ajustado para condições isocinéticas no bocal da sonda de amostragem. Com um volume de amostragem de cerca de10 $\mathrm{m}^{3}$ pode-se atingir o limite de deteç̧ão de 1 a 5 pg I-TEQ/m $\mathrm{m}^{3}$.

Outros métodos de amostragem encontram-se na norma técnica da União Europeia, EN 1948, parte 1 [2] e do US-EPA Reference Modified Method 23, PCDD \& PCDF.

As amostras são analisadas de acordo com a EN 1948 parte 2 e 3. As determi- figura 2 Amostragem de Dioxinas/furanos: método da sonda arrefecida

nações quantitativas de PCDD/PCDF são feitas de acordo com o método de diluição isotópica recorrendo aos seguintes padrões internos: (ver quadro 1)

Os compostos são extraídos dos condensados, da espuma e do filtro, com solventes apropriados. 0 procedimento de remoção de interferentes da amostra é conseguido através de sistemas de multicolunas cromatográficas. As determinações analíticas foram efectuadas em equipamento HRGC/HRMS, VG-AutoSpec utilizando colunas capilares DB5. São determinados os seguintes congéneres: (ver quadro 2)

A parte de determinação das concentraçōes no laboratório, exige também equipamento adequado. 0 processo das análises laboratoriais tem de dominar as dificuldades seguintes $[7,8]$ :

- as dioxinas/furanos encontram-se nas amostras em quantidades muito baixas na ordem dos pg (picogramas $=10^{12} \mathrm{~g}$ ) ou dos $\mathrm{fg}$ (fentogramas $=$ $10^{-15} \mathrm{~g}$ )

- em geral as dioxinas/furanos são acompanhadas dos compostos orgânicos de características química semelhantes, sendo essencial o procedimento de clean up, de modo a remover possiveis interferentes.

- para cada um dos 2,3,7,8-congéneres, que em parte contribuí para o calculo da toxicidade (International 
Toxic Equivalent Factor, ver tabela 1), é imprescindivel a determinação e quantificação exacta.

Estas condições exigem um procedimento definido, que é determinado nas normas técnicas especificando as medições das dioxinas/ furanos na Europa (EN 1948, parte 2 e 3) e nos EUA (USEPA Reference Method 613). Os procedimentos incluem as seguintes processos:

• extracção da amostra com um solvente orgânico para permitir a concentração das dioxinas/ furanos no extracto.

- purificação do extracto para separação de substâncias indesejadas (clean-up) recorrendo a colunas cromatográfica adequadas.

- concentração das dioxinas /furanos para evaporação do solvente.

- determinação e quantificação para cada um dos 2,3,7,8- congéneres com um equipamento sendo este composto dum espectrômetro de massa acoplado a um cromatógrafo a gás, ambos os equipamentos de alta resolução.

A quantificação é baseada na adição de substâncias padrão, numa quantidade bem conhecida adicionada às amostras, antes da extracção (método do padrão interno). A vantagem do método do padrão interno é que prováveis perdas de PCDD/PCDF durante o processo de purificação e limpeza durante o processo da purificação são compensadas usando este método. As substâncias padrão, têm exactamente a mesma estrutura química das dioxinas / furanos, mas os átomos de carbono são compostos dos isótopos C-13, de modo que a molécula tem uma massa diferente. A distinção entre a amostra das dioxinas/furanos e os da substancia padrão é realizada recorrendo-se com o espectrómetro de massa.

\section{b) PAHs e PCBs}

A metodologia de amostragem para os PAHs e PCBs é baseada na EN 1948 Método da sonda arrefecida. Sendo, no entanto, uma amostragem bastante

\section{Quadro 1}

2,3,7,8 tetra-CDD

1,2,3,7,8 Penta-CDD

1,2,3,6,7,8 Hexa-CDD

$1,2,3,4,7,8$ Hexa-CDD

1,2,3,4,6,7,8 Hepta-CDD

1,2,3,4,6,7,8,9 Octa-CDD

2,3,7,8 Tetra-CDF
2,3,4,7,8 Penta-CDF

1,2,3,4,7,8 Hexa-CDF

1,2,3,6,7,8 Hexa-CDF

2,3,4,6,7,8 Hexa-CDF

1,2,3,4,6,7,8 Hepta-CDF

$1,2,3,4,6,7,8,9$ Octa-CDF

\section{Quadro 2}

\begin{tabular}{ll}
\hline 2,3,7,8 tetra-CDD & $2,3,4,7,8$ Penta-CDF \\
$1,2,3,7,8$ Penta-CDD & $1,2,3,4,7,8$ Hexa-CDF \\
$1,2,3,6,7,8$ Hexa-CDD & $1,2,3,6,7,8$ Hexa-CDF \\
$1,2,3,4,7,8$ Hexa-CDD & $1,2,3,7,8,9$ Hexa-CDF \\
$1,2,3,7,8,9$ Hexa-CDD & $2,3,4,6,7,8$ Hexa-CDF \\
$1,2,3,4,6,7,8$ Hepta-CDD & $1,2,3,4,6,7,8$ Hepta-CDF \\
$1,2,3,4,6,7,8,9$ Octa-CDD & $1,2,3,4,7,8,9$ Hepta-CDF \\
2,3,7,8 Tetra-CDF & $1,2,3,4,6,7,8,9$ Octa-CDF \\
$1,2,3,7,8$ Penta-CDF & \\
\hline
\end{tabular}

mais curta, cerca de uma hora. São determinados os seguintes PAHs de acordo com a EPA:

Naftaleno Benzo(a)antraceno,
Acenaftaleno Criseno,
Acenafteno Benzo(b)fluoranthen,
Fluoreno Benzo(k)fluoranteno,
Fenantreno Benzo(a)pireno,

Antraceno Indeno(1,2,3)-cd-pireno,

Fluoranteno Benzo(ghi)perileno,

Pireno Dibenzo(ah)antraceno

Recorrendo á amostragem isocinética através do trem de amostragem adequado são recolhidas amostras representativas. As partículas são recolhidas num filtro é a fase gasosa é colhida por condensação através de um adsorvente.
Após a recolha da amostra representativa o trem de amostragem é descontaminado por passagem de água e acetona recolhendo-se juntamente com os filtros e adsorventes sendo posteriormente extraídos com um solvente orgânico por extracção de soxleht. 0 extracto final é concentrado por rota vapor.

É necessário a limpeza para remoção de interferentes do extracto final antes da análise cromatográfica por HRGC/MS com colunas capilares DB-5. A quantificação é conseguida através da adição de padrões internos e externos.

São adicionados aos extractos os seguintes padrões internos deuterados.

- Naftaleno

D8

- Acenaftaleno D10

- Fenantreno D10 

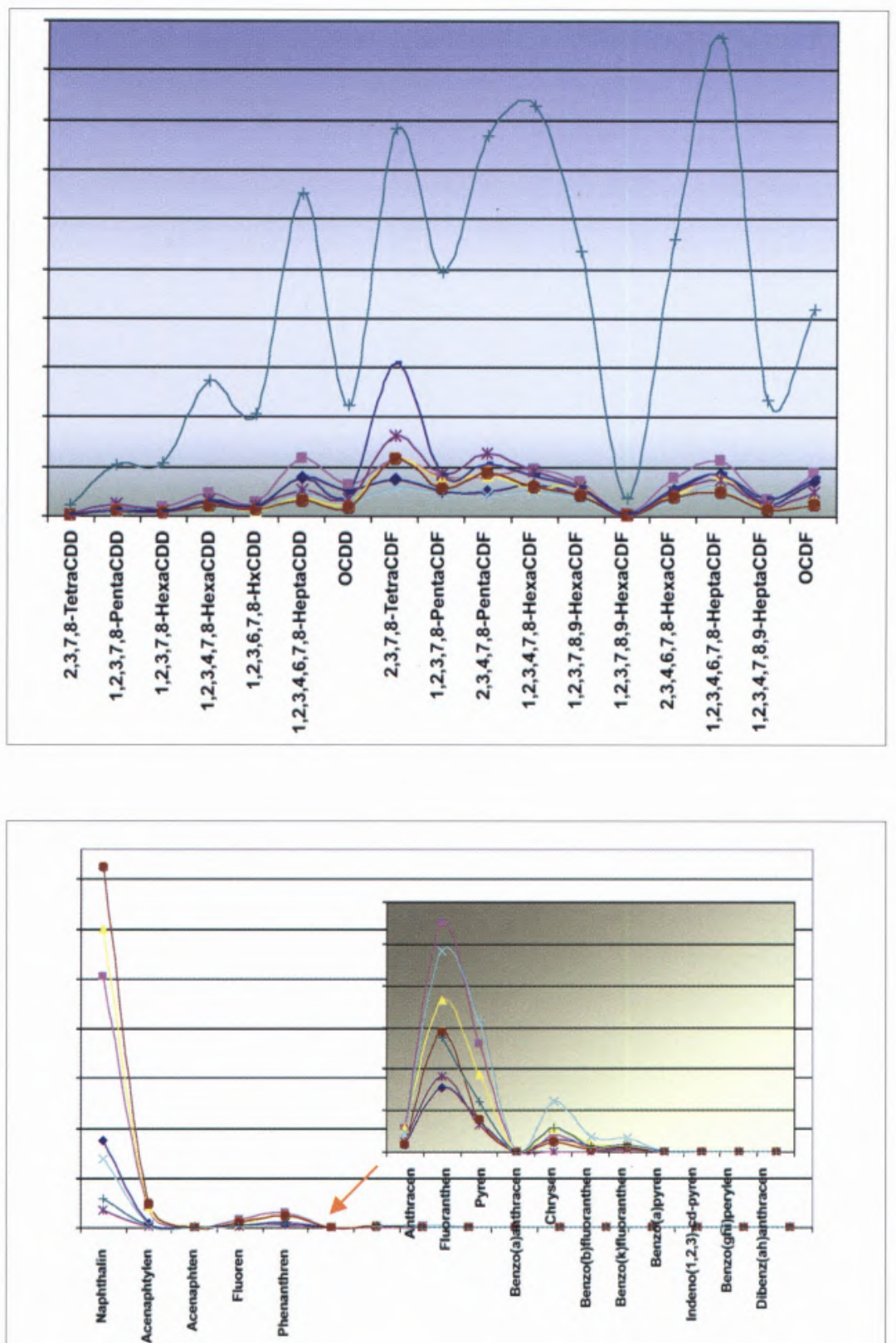

- Pireno

D10

2,2', 3,4, 4', 5'-Hexa-PCB (PCB-138)

${ }^{13} \mathrm{C}-\mathrm{UL}$

- Benzo(k)fluoranteno

D12

2,2', 4, 4',5, ' '-Hexa-PCB (PCB-153)

${ }^{13} \mathrm{C}-\mathrm{UL}$

- Benzo(a)pireno

D12

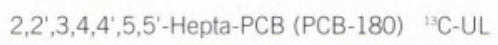

- Dibenz(ah)antraceno

D14

- Benzo(ghi)perileno

D12

Com a mesma amostra são determinados os PCB 28, 52, 101, 138, 153 e 180 bem como os homólogos totais. Para a quantificação são adicionados à amostra os seguintes padrões internos:

\section{2,4,4'-Tri-PCB (PCB-28)}

${ }^{13} \mathrm{C}-\mathrm{UL}$

2,2',5,5'-Tetra-PCB (PCB-52)

${ }^{13} \mathrm{C}-\mathrm{UL}$

2, 2', 4,5,5'-Penta-PCB (PCB-101)

${ }^{13} \mathrm{C}-\mathrm{UL}$
Após a adição as amostras são extraídas com solventes adequados a análises vestigiais (ex. nanograde). 0 procedimento posterior é o mesmo efectuado para os PAHs: Remoção de interferentes num sistema de multicolunas cromatográficas e posterior análise por HRGC/MS

\section{c) Metais pesados}

Para os metais pesados como cobre, chumbo, cádmio, níquel, arsênio, ferro, figura 3 Perfil caracteristico (fingerprint) dos 17 congéneres de dioxinas/furanos

figura 4 Perfil característico dos 16 compostos de PAHs

zinco e outros a metodologia é baseada na EPA 5, EPA 12 e EPA 60. A amostragem é isocinética como para as dioxinas/furanos, PAHs e PCBs mas a sonda não é arrefecida, neste caso a sonda é mantida a uma temperatura superior á temperatura ambiente não ocorrendo a condensação dos efluentes gasosos em particular da água[6,7].

$\mathrm{O}$ gás passa na sonda e as partículas e metais são recolhidos num filtro de quarto, posteriormente o gás é recolhido em quatro borbulhadores que são mergulhados num banho de gelo para promover a condensação e possibilitar a recolha dos gases. A análise laboratorial é efectuada 
Tabela 2- Propriedades físico-químicas dos PAHs

\begin{tabular}{|c|c|c|c|c|c|}
\hline PAHs & $\begin{array}{l}\mathrm{N} .^{\circ} \\
\text { de anéis }\end{array}$ & $\begin{array}{l}\text { Mr. (aprox) } \\
\mathrm{g} / \mathrm{mol}\end{array}$ & $\begin{array}{l}\text { Ponto } \\
\text { de fusão }{ }^{\circ} \mathrm{C}\end{array}$ & $\begin{array}{l}\text { Ponto de } \\
\text { ebulição }{ }^{\circ} \mathrm{C}\end{array}$ & $\begin{array}{l}\text { Formula } \\
\text { química }\end{array}$ \\
\hline Naftaleno & 2 & 128 & 80.6 & 218 & $\mathrm{C} 10 \mathrm{H} 8$ \\
\hline Acenaftaleno & 3 & 152 & 94 & 265 & $\mathrm{C} 12 \mathrm{H} 8$ \\
\hline Fenantreno & 3 & 178 & 99.5 & 340 & $\mathrm{C} 14 \mathrm{H} 10$ \\
\hline Fluoreno & 3 & 166 & 116 & 295 & $\mathrm{C} 13 \mathrm{H} 10$ \\
\hline Acenafteno & 3 & 154 & 95 & 279 & $\mathrm{C} 12 \mathrm{H} 10$ \\
\hline Antraceno & 3 & 178 & 217 & 370 & $\mathrm{C} 14 \mathrm{H} 10$ \\
\hline Fluoranteno & 4 & 202 & 110.8 & 375 & $\mathrm{C} 16 \mathrm{H} 10$ \\
\hline Pireno & 4 & 202 & 156 & 404 & $\mathrm{C} 16 \mathrm{H} 10$ \\
\hline Criseno & 4 & 228 & 255 & 448 & $\mathrm{C} 18 \mathrm{H} 12$ \\
\hline Benzo(a)antraceno & 4 & 228 & 159.8 & 437.6 & $\mathrm{C} 18 \mathrm{H} 12$ \\
\hline Benzo(a)pireno & 5 & 252 & 176 & 495 & $\mathrm{C} 2 \mathrm{OH} 12$ \\
\hline Dibenzo(a,h)antraceno & 5 & 278 & 266 & 524 & $\mathrm{C} 22 \mathrm{H} 14$ \\
\hline Benzo[k]fluoranteno & 5 & 252 & 215.7 & 480 & $\mathrm{C} 2 \mathrm{OH} 12$ \\
\hline Benzo[b]fluoranteno & 5 & 252 & 167 & 357 & $\mathrm{C} 2 \mathrm{OH} 12$ \\
\hline Indeno(1,2,3)-cd-pireno & 6 & 276 & 162.5 & 536 & $\mathrm{C} 22 \mathrm{H} 12$ \\
\hline Benzo(g,h,i)perileno & 6 & 276 & 278 & 500 & $\mathrm{C} 22 \mathrm{H} 12$ \\
\hline
\end{tabular}

por ICP após a digestão ácida com ácido nítrico, clorídrico e finalmente perclórico da solução recolhida e dos filtros.

\section{Apresentação de resultados e discussão:}

De modo a relacionar a composição da sucata com as emissões de micropoluentes mediram-se os teores de Dioxinas/Furanos em sucata contendo maio- ritariamente 4 tipos de sucatas: sucata contendo óleos perfurantes, sucata contendo PVCs (proveniente da industria automóvel), sucata sem cloro mas com adição de cloreto de cálcio, $\mathrm{CaCl} 2$ e sucata "sem cloro". As amostragens tiveram uma duração de 6 horas (volume amostrado de $10 \mathrm{Nm} 3$ ) usando os procedimentos descritos anteriormente. As condições de amostragem (temperatura, pressão e fluxo) não revelaram varia- ções significativas. Para estas variantes de sucata foram efectuadas medições de efluentes gasosos antes e depois da unidade de despoeiramento, tendo os resultados obtidos sido concordantes com os pressupostos teóricos de que sucata com elevada contaminação de compostos clorados aumenta significativamente a quantidade de dioxinas totais encontradas. Os resultados obtidos são sempre superiores para as medições

figura 5 Perfil característico obtido para os PCBS

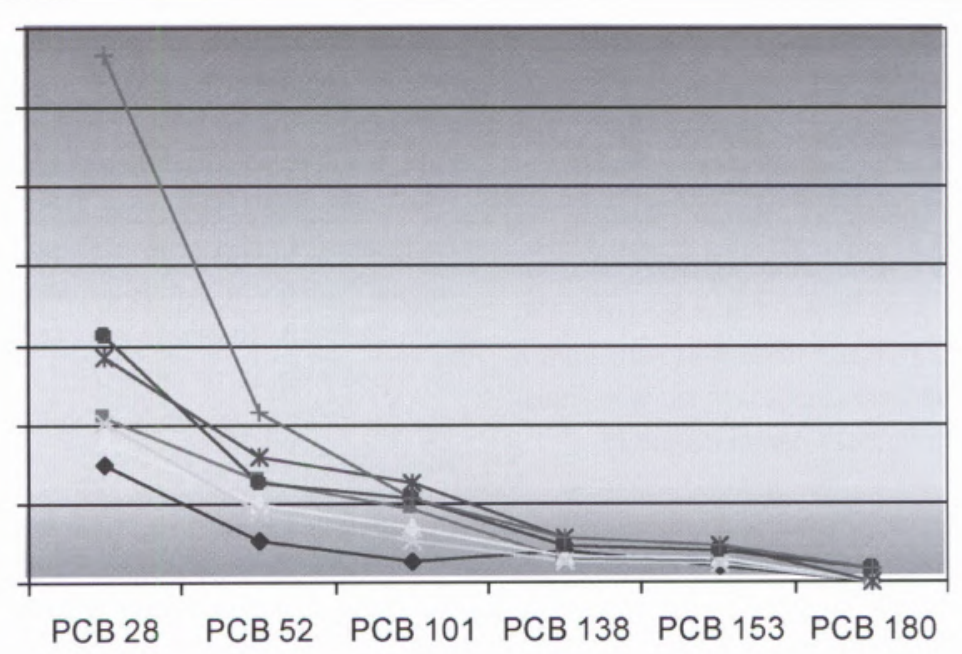




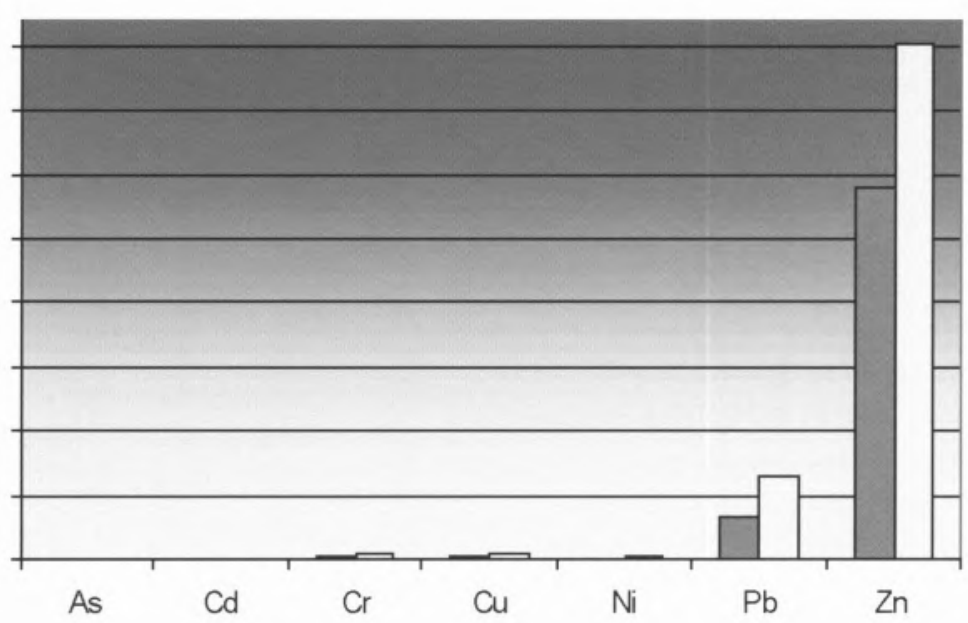

efectuadas antes da unidade de despoeiramento relativamente ás efectuadas após essa mesma a unidade. Nas variações de sucata por tipo, os valores mais elevados foram registadas para a sucata com PVC, seguindo-se a sucata com óleos de perfuração, (aproximadamente 20 vezes inferiores ao da sucata com PVC) sendo os valores encontrados para os restantes bastante aproximados.

Após este estudo foram realizadas medições com a composição de sucata típica nesta indústria, tendo sido pesquisado os teores de dioxinas/furanos, PAHs e PCBs e metais pesados. Das medições realizadas efectuou-se um gráfico que permite concluir a existência de dioxinas e furanos, destacando-se o 2,3,4,7,8 pentaCDF como o composto maioritário detectado no conjunto das medições realizadas. 0 gráfico seguinte revela a presença dos 17 congéneres pesquisa- dos e que se encontram presentes em todas as medições efectuadas.

Os valores encontrados não são homogéneos, existindo dispersão de resultados quer para os congéneres individuais quer para o total de dioxinas/furanos. No entanto, observando o gráfico, verifica-se a existência de um perfil bastante coerente, independente do fluxo e da capacidade do próprio forno. Os resultados das medições de PAHs, apresentados na figura 4, revelam um perfil característico de emissões de PAHs. Por análise do gráfico da figura 4 destacam-se o Naftaleno, Acenaftaleno, Fenantreno, Fluoreno, como compostos maioritários encontrando-se outras espécies como Fluoranteno, Pireno, Acenafteno e Criseno em quantidades mais baixas.

Dos compostos pesquisados não foram detectados o Benzo(a)pireno, Indeno(1,2,3)-cd-pireno, Benzo(ghi)perile- figura 5 Resultados das medições de metais pesados

no, Dibenzo(a,h)antraceno. Fazendo um zoom do gráfico, a partir do Antraceno revela-se um perfil característico também para estes compostos. Novamente, o conjunto das várias medições efectuadas revela um perfil coerente e estável. No entanto, estes resultados são idênticos entre as várias amostragens, independentemente da concentração obtida, culminando num perfil típico de emissões de PAHs.

Analisando a tabela 2, confirma-se que os compostos que não aparecem nas emissões gasosas são de facto os compostos com 5 e 6 anéis que se encontram agregados ás partículas e que são capturadas pelos filtros de mangas, não sendo deste modo emitidos.

No entanto em algumas medições estes mesmos compostos aparecem em quantidades ínfimas. A razão prende-se com o facto de, como referido anterior-

Tabela 3- Propriedades físico-químicas dos PCBs [8]

\begin{tabular}{lllllll}
\hline PCBs & $\begin{array}{l}\mathbf{N} .^{\circ} \text { de átomos } \\
\text { de cloro }\end{array}$ & $\begin{array}{l}\text { Massa } \\
\text { molecular }\end{array}$ & $\begin{array}{l}\text { Ponto de } \\
\text { ebulição }{ }^{\circ} \mathbf{C}^{\mathbf{a}}\end{array}$ & $\begin{array}{l}\text { Ponto de } \\
\text { fusão }{ }^{\circ} \mathbf{C}\end{array}$ & $\begin{array}{c}\text { Pressão de } \\
\text { vapor }(\mathbf{P a}) \text { a } \mathbf{2 5}{ }^{\circ} \mathbf{C}\end{array}$ & $\begin{array}{l}\text { Taxa de evaporação } \\
\text { a 25 }{ }^{\circ} \mathbf{C}\left(\mathbf{g} /\left(\mathbf{m}^{2} \mathbf{h}\right)\right.\end{array}$ \\
\hline PCB 28 & 3 & 256 & $28-87$ & 337 & 0.054 & 0.017 \\
PCB 52 & 4 & 290 & $47-180$ & 360 & 0.012 & $4.2 \times 10^{-3}$ \\
PCB 101 & 5 & 324 & $76.5-124$ & 381 & $2.6 \times 10^{-3}$ & $1.0 \times 10^{-3}$ \\
PCB 138 & 6 & 358 & $77-150$ & 400 & $5.8 \times 10^{-4}$ & $2.5 \times 10^{-4}$ \\
PCB 153 & 6 & 358 & $77-150$ & 400 & $5.8 \times 10^{-4}$ & $2.5 \times 10^{-4}$ \\
PCB 180 & 7 & 391 & $122.4-149$ & 417 & $1.3 \times 10^{-4}$ & $6.2 \times 10^{-5}$ \\
\hline
\end{tabular}

a intervalo de temperaturas para isómeros com o mesmo $\mathrm{n} .^{\circ}$ de átomos de cloro 
mente, estes compostos se encontrarem agregados ás partículas que ficam retidas no filtro de mangas (do sistema de despoeiramento) no entanto existe sempre uma pequeníssima fracção que é emitida e capturada pelos filtros do trem de amostragem, sendo posteriormente quantificada aquando das análises uma vez que se analisa quer a solução quer as partículas capturadas. Os resultados das mediçōes de PCBs revelam um decréscimo na concentração à medida que aumentam o n. ${ }^{\circ}$ de cloros, conforme ilustrado na figura 5.0 s compostos maioritários são os que possuem menor $\mathrm{n} .{ }^{\circ}$ de cloros.

Tendo em conta as propriedades físico-químicas dos compostos estes resultados são coerentes. Ponto de ebulição e de fusão aumentam com o n. ${ }^{\circ}$ de cloros, bem como a massa molecular, a pressão de vapor e taxa de evaporação a $25^{\circ} \mathrm{C}$ diminuem à medida que aumenta o $n . .^{\circ} \mathrm{de}$ cloros e a nível de emissōes denota-se uma diminuição da concentração.

Em relação aos metais pesados destacam-se o zinco, Zn, e o chumbo, Pb, como compostos maioritários, seguindo-se o crómio, cobre e o níquel.

\section{Conclusões:}

Estudos anteriores referem que a quantidade de dioxinas está directamente relacionada com: a velocidade de arrefecimento dos gases de saída especialmente a volta de $300^{\circ} \mathrm{C}$, a quantidade de poeiras, os metais vestigiais especialmente o cobre que é um bom catalizador nas reacções de formação de dioxinas, o carbono e cloro encontrado nas poeiras e a presença de oxigénio.

Constata-se que as poeiras recolhidas pelos filtros contêm carbono, cloro (na forma de sais) e metais em quantidades vestigiais. Constata-se também a presença de metais pesados ao longo deste estudo, proporcionando-se as condições para que ocorram a formação de PCDD/PCDF através da sintese de De Novo. No entanto, os valores encontrados de PAHs e PCBs revelam potenciais percursores de dioxinas. Considerando o facto de os PAHs se distribuírem entre a fase gasosa e de partículas é importante para o esclarecimento do mecanismo de formação de PCDD/PCDF a futura análise das poeiras capturadas pelos filtros de mangas do sistema de despoeiramento relativamente a estes compostos. Assim consideram-se possiveis dois mecanismos de formação de PCDDs/PCDFs no forno de arco eléctrico:

- Reacções heterogéneas de determinados precursores orgânicos (ex clorofenois, PCBs, clorobenzenos) na superfície das partículas a temperaturas superiores a $300^{\circ} \mathrm{C}$. Estes percursores entram no processo através das impurezas da sucata tais como tintas, óleos perfurantes e plásticos. Elevadas emissões de PCDD e PCDF foram encontrados quando se realizaram medições com sucata contaminada com PVC.

- A síntese De Novo sem precursores orgânicos. Formação através de carbono, oxigénio e cloreto de metais a temperaturas de $250^{\circ} \mathrm{C}$. Neste caso os cloretos de metal actuam como catalisadores. OS PCDD/PCDF são líquidos extremamente viscosos a temperaturas inferiores a $300^{\circ} \mathrm{C}$ e podem facilmente ser adsorvidos na superfície das partículas.

Os estudos efectuados permitiram, até agora, tirar conclusōes importantes sobre a influência das variáveis operacionais sobre as emissões dos compostos orgânicos atrás mencionados. Foi ainda possível determinar o perfil característico ("fingerprint") das emissōes de compostos orgânicos para as dioxinas/dibenzofuranos, PAHs e PCBs. De facto, apesar da variabilidade registada em campanhas de amostragem sucessivas, é possível verificar a ocorrência de um perfil regular das emissões destes compostos que se considera ser uma informação básica para esclarecimento dos mecanismos de formaçāo/destruição, assim como da influência das condições operacionais e, consequentemente, para poder delinear estratégias de reduçāo dos respectivos niveis de emissão. De facto, para sucatas não contaminadas, onde, à partida, não existem percursores, os dados parecem indicar para a possibilidade da ocorrência de reacções heterogéneas na superficie das partículas a temperaturas supe- riores a $300^{\circ} \mathrm{C}$. Contudo, uma vez que a temperatura no forno é superior a 1500 ${ }^{\circ} \mathrm{C}$ deverá ocorrer, posteriormente, a destruição de algumas das espécies formadas. Parece estarem reunidas as condições básicas para a ocorrência da síntese De Novo (sem percursores orgânicos), mecanismo esse que poderá ser amplificado a temperaturas superiores a $250^{\circ} \mathrm{C}$ e pela ocorrência de espécies metálicas que actuem como catalisadores.

\section{Bibliografia}

[1] - Bordado, J.C.M., Ferreira, H.M.S., Gomes, J.F.P., "Dioxinas e dibenzofuranos no meio Ambiente", Química, 72, 15/19 (1999)

[2] - European Standard: CEN/ EN 1948, September 1996, - Stationary source emissions - Determination of the mass concentration of PCDD/ PCDFs Part 1: Sampling

[3] - AEA Technology, "Compilation of EU Dioxin Exposure and Health Data", Abingdon, 1999

[4] - European Standard: CEN/ EN 1948, September 1996, - Stationary source emissions - Determination of the mass concentration of PCDD/ PCDFs Part 2: Extraction and clean-up

[5] - European Standard: CEN/ EN 1948, September 1996, - Stationary source emissions Determination of the mass concentration of PCDD/ PCDFs Part 3: Identification and quantification

[6] - Gomes, J.F.P., "Poluição Atmosférica Um Manual Universitário", Ed. Publindústria, Porto, 2001

[7] - Gomes, J.F.P., "Qualidade do Ar", Livro texto, Ediçōes Técnicas ISQ, Lisboa, 1993,

[8] - Erickson, Mitchell D. - 'Analytical Chemistry of PCBs", Lewis Publishers 1997, 2nd edition

\section{Agradecimentos}

Trabalho efectuado ao abrigo do Contrato 7210-PR-200 - Projecto ECSC P4201 